\title{
Viabilidade do Ensino Padronizado no Conteúdo de Estomaterapia na Graduação de Enfermagem: Proposta de Objeto de Aprendizagem Online
}

\author{
Viability of Standardized Education in Stomatherapy Content Undergraduate \\ Nursing: Proposal Object Online Learning
Viabilidad de Estandarizado Educación en Estomaterapia Contenido Pregrado Enfermería: Propuesta de Objetos de Aprendizaje en Línea

\author{
Julia Drummond de Camargo', Raquel Acciarito Motta ${ }^{2}$
}

\begin{abstract}
RESUMO
O avanço tecnológico e científico referente ao tratamento de feridas, estomias e incontinência vem aumentando consideravelmente, sendo necessária a preparação dos profissionais de enfermagem para as questões éticas e de conhecimento teórico-prático neste segmento. O interesse em propor um ensino padronizado e direcionado ao cuidado em estomaterapia, que congregue várias informações sobre o tema, tendo como subsídio o uso de Objeto de Aprendizagem (OA), converge com a otimização do tempo e do aprendizado dos alunos,visto que nem todos os docentes de enfermagem tem essa especialização. O objetivo deste estudo foi verificar a viabilidade da padronização do ensino sobre estomaterapia no curso de enfermagem com auxílio de objeto de aprendizagem online junto aos docentes da graduação. Trata-se de uma pesquisa de campo, descritiva, com abordagem mista, aprovada pelo Comitê de Ética e Pesquisa (CoEP - n 618.806/14). A coleta de dados foi realizada no período de abril e maio de 2014 no Centro Universitário São Camilo, através de cartas convite enviadas pela Coordenação de Enfermagem a 40 docentes do Curso contendo o TCLE e link do questionário online (Google Docs). Quanto aos resultados, dos 18 docentes que responderam o questionário, 78\% tinham mais de 20 anos de formação e nenhum especialista em estomaterapia. A análise dos dados revelou como principal resultado que 78\% utilizariam o OA em suas aulas. Conclui-se que a elaboração e criação de um protocolo para ensino de estomaterapia na graduação em enfermagem por meio de objeto interativoonline seria viável e auxiliaria no processo ensino-aprendizagem.
\end{abstract}

DESCRITORES: Estomaterapia. Educação em Enfermagem. Cuidados de Enfermagem. Aprendizagem.

\begin{abstract}
The technological and scientific advances related to wound care, ostomy and incontinence is increasing considerably, requiring the preparation of nurses for the ethical and theoretical and practical knowledge in this segment. The interest in offering a standardized education and targeted care in stomatherapy, bringing together various information on the subject, with the allowance the use of Learning Objects $(\mathrm{OA})$, converges with the optimization of time and student learning, as not all nursing faculty has this expertise. The objective of this study was to determine the feasibility of standardizing the teaching on stomatherapy in nursing program with online learning object aid from the graduation teachers. This is a field research, descriptive, with mixed approach, approved by the Research Ethics Committee (COEP - No. 618,806/14). Data collection took place between April and May 2014 in Centro Universitário São Camilo,
\end{abstract}

${ }^{1}$ Centro Universitário São Camilo. Hospital Sírio Libânes - São Paulo (SP), Brasil. Endereço para correspondência: Rua João Batista Leme da Silva, 57, CEP: 05449-030 - Vila Madalena - São Paulo (SP), Brasil - E-mail: julia_drummond07@hotmail.com

Ensino à Distância do Centro Universitário São Camilo - São Paulo (SP), Brasil.

Artigo recebido em: 07/03/2015 - Aceito para publicação em: 09/06/2015 
by invitation letters sent by the Nursing Coordination to 40 teachers of the course containing the IC and link to the online questionnaire (Google Docs). As for the results, of the 18 teachers who responded to the questionnaire, 78\% were over 20 years of training and no specialist stomatherapy. Data analysis revealed main result that $78 \%$ would use the OA in their classes. We conclude that the development and creation of a protocol for stomatherapy education in undergraduate nursing through online interactive object would be feasible and would help in the teaching-learning process.

DESCRIPTORS: Stomatherapy. Education, Nursing. Nursing Care. Learning.

\section{RESUMEN}

Los avances tecnológicos y científicos relacionados con el cuidado de heridas, ostomía e incontinencia están considerablemente aumentando, lo que requiere la preparación de las enfermeras con relación a los conocimientos ético, teórico y práctico en este segmento. El interés por ofrecer una educación estandarizada y dirigida a la atención en estomaterapia, que recompile diversas informaciones sobre el tema, con la asignación del uso de Objetos de Aprendizaje, converge con la optimización del tiempo y del aprendizaje de los estudiantes, ya que ni todos los profesores de enfermería tienen esta experiencia. El objetivo de eso estudio fue determinar la viabilidad de estandarizar la enseñanza de estomaterapia en el programa de enfermería con el suporto del objeto de aprendizaje en línea con los maestros de pregrado. Se trató de una investigación de campo, descriptiva, con enfoque mixto, aprobada por el Comité de Ética e Investigación (618.806/14). La recolección de datos se llevó a cabo entre abril y mayo del 2014 en el Centro Universitário São Camilo, por medio de las cartas de invitación enviadas por la Coordinación de Enfermería a 40 profesores del curso que contiene el consentimiento informado y el enlace al cuestionario en línea (Google Docs). En cuanto a los resultados de los 18 profesores que respondieron al cuestionario, el 78\% tenía más de 20 años de formación y ninguno era especialista en estomaterapia. El análisis de datos reveló como principal resultado que 78\% usaría el Objeto de Aprendizaje en sus clases. Se concluye que el desarrollo y la creación de un protocolo para la educación sobre estomaterapia en enfermería de pregrado, a través del objeto interactivo en línea, serían factibles y podrían ayudar en el proceso de enseñanza-aprendizaje.

DESCRIPTORES: Estomaterapia. Educación en Enfermería. Atención de Enfermería. Aprendizaje.

\section{INTRODUÇÃO}

$\mathrm{O}$ avanço tecnológico e científico referente à prevenção e tratamento de feridas vem se ampliando, e inúmeras inovações surgem no mercado a cada dia, tornando necessária a atualização constante de profissionais da saúde e, especialmente, os enfermeiros que atuam nessa dimensão assistencial ${ }^{1}$.

Além do cuidado com feridas (procedimento feito em larga escala pela enfermagem), a assistência ao paciente com estomias ou incontinências também fazem parte da gama de conteúdos abordados na área de Estomaterapia. Caso estes cuidados sejam atribuídos à enfermagem, passa a ser necessária a preparação adequada dos profissionais para lidar com cada situação, incluindo tanto questões éticas quanto de conhecimento teórico-prático, além do constante aprimoramento de enfermeiros e a atualização docente.

A complexidade e a diversidade das ações assistenciais, assim como as novas exigências do mercado de trabalho, induzem a uma reflexão sobre a formação profissional. Neste sentido, é sabido que, durante o período de estágio curricular da graduação em enfermagem, o docente ensina e vivencia com os alunos o cuidado, transcendendo seu significado e expressando muito mais do que simplesmente cuidar. Afinal, realizar procedimentos como cuidar de feridas, estomias e incontinência não é uma tarefa automatizada, mas, sim, reflexiva; necessitando de um conhecimento teórico relacionado à fisiologia da pele, dos produtos existentes no mercado e daqueles que são padronizados no serviço de saúde ou hospital, de forma que estes procedimentos não podem ser realizado apenas como ação meramente técnica, pois envolvem a relação, mesmo que temporária, entre dois seres humanos ${ }^{2,3}$.

Com isso, surge a importância do ensino padronizado e direcionado, com objetivos bem definidos para proporcionar o aprendizado adequado visando o desenvolvimento profissional do aluno, sendo o protocolo, com uso dos conceitos corretos, estratégias e dinamicidade, um dos principais instrumentos que poderá auxiliá-los.

$\mathrm{Na}$ elaboração de um protocolo, é fundamental ter claro o objetivo do mesmo, uma vez que este trabalho requer, além do conhecimento, a disciplina, a paciência e o trabalho em equipe ${ }^{4}$. Sua utilização deverá ser disseminada com a finalidade de se obter uma unidade de pensamento frente ao exposto.

Como o uso de recursos tecnológicos na educação vem agregando valor ao ensino, pensou-se ser este o caminho viável para se otimizar o aprendizado de estomaterapia por 
Por se tratar de um tema extenso, a palavra estomaterapia

alunos de graduação, principalmente com o uso de Objetos de Aprendizagem (OA) online. Entende-se, portanto, que a gama de procedimentos que envolvem o cuidado de enfermagem nesta especialidade são extensos e diversos. Assim, optou-se inicialmente por verificar a viabilidade do ensino padronizado com uso de OA online de forma genérica, trazendo essa dimensão assistencial que tal especialidade carrega, já que estas atribuições estão contidas no dia a dia do enfermeiro na assistência.

De acordo com a terminologia adotada pelo Learning Technology Standards Committee (LTSC) do Institute of Electrical and Electronics Engineers (IEEE), os OA's são definidos como uma entidade digital ou não, que poderá ser usada ou reutilizada durante um processo de suporte tecnológico ao ensino e aprendizagem. Alguns exemplos desta tecnologia incluem a aprendizagem interativa, sistemas instrucionais assistidos por computadores inteligentes, sistemas de educação à distância e ambientes de aprendizagem colaborativa ${ }^{5}$.

Define-se que a utilização de um OA constitui um ponto de partida para promover, no aluno, o interesse e a curiosidade em aprofundar seus conhecimentos e não deve-se esquecer que a inclusão digital é um importante estímulo ao processo de aprendizagem dos estudantes e devem reunir características como durabilidade, facilidade para atualização, flexibilidade, modularidade, portabilidade, entre outras ${ }^{6,7}$.

Neste contexto, mediante o interesse no assunto, as experiências de sala de aula e a observação feita pela autora em sua graduação quanto as diferentes estratégias e recursos de ensino usados para abordar os temas relacionados a estomaterapia, seja em aulas teóricas, práticas ou nos estágios, pôde-se perceber que havia uma grande quantidade de conteúdo sobre o tema que deveria ter sido abordado e não foi, mediante fatores que destinavam tal situação, como: carga horária insuficiente, a superficialidade no trato do assunto pelo docente e o tema aparecer em matérias e semestres diferentes de forma fragmentada, desconexa da assistência sistematizada.

Assim, o estudo mostra-se relevante pois, ao ser investigada a percepção docente sobre a viabilidade de um protocolo de ensino nas áreas da estomaterapia para estudantes de graduação em enfermagem com uso de recurso tecnológico online $(\mathrm{OA})$, pôde-se tentar garantir a uniformidade $\mathrm{e}$ a consonância da prática assistencial à realidade atual, esperando obter o melhor preparo dos alunos, visto que nem todos os docentes são especialistas no assunto. foi abordada nos questionamentos junto aos docentes como intuito de fazê-los visualizar o conceito como um todo e não fragmentado pelas três áreas que o compõem: ferida, estomias e incontinência, numa tentativa de fazer os sujeitos refletirem sobre a grandeza de tais temas e suas ações, próprias dos enfermeiros, que poderão ser utilizados no ensino com qualidade, de forma atrativa e interativa, com o uso de Objetos de Aprendizagem Online.

Como neste aspecto o docente é o responsável pelas escolhas que faz em seu planejamento de ensino, o envolvimento destes no preparo de um material para os estudos online é de extrema importância. Assim, surgiram as seguintes questões problema: $\mathrm{O}$ docente julga ser importante o ensino da estomaterapia na graduação em enfermagem? Ele acredita que o ensino com conteúdo padrão pode melhorar o aprendizado do aluno? Ele acha viável a implantação de um protocolo de ensino através de objeto de aprendizado, visando a aprendizagem ampla e padronizada?

\section{OBJETIVO}

Verificar a viabilidade do ensino padronizado de estomaterapia para a graduação em enfermagem com auxílio de objeto de aprendizagem junto aos docentes de graduação, permitindo a construção consciente e democrática do mesmo para seu uso racional.

\section{MÉTODO}

Trata-se de uma pesquisa de campo, descritiva, com abordagem mista (quali-quantitativa), onde foram exploradas, junto aos docentes do Curso de Enfermagem de um Centro Universitário situado na Cidade de São Paulo, questões sobre a viabilidade da implantação de um protocolo de ensino sobre estomaterapia.

Após elaborado, o projeto foi enviado para o Comitê de Ética e Pesquisa (CEP), sendo aprovado através do parecer $\mathrm{n}^{\circ}$ 618.806/14.

A pesquisa foi dividida em três etapas: solicitação de autorização da coordenação do curso de graduação de enfermagem, através do envio, por e-mail, da Carta de autorização do coordenador do curso de graduação de enfermagem para realização da pesquisa, Carta de autorização da instituição 
para realização da pesquisa; e o envio, por e-mail de uma carta convite para a pesquisa aos docentes que participaram da pesquisa. A segunda etapa foi o envio do Termo de Consentimento Livre e Esclarecido (TCLE), juntamente com o instrumento de coleta de dados de questionário online (confeccionado contendo perguntas abertas e fechadas sobre o tema proposto no estudo), onde, através de e-mail, foi enviado um link para o Google Docs, que continha o acesso as questões.

O Google Docs é um processador de textos e planilhas baseado na web, que permite a criação e edição de questionários online e a elaboração de resultados em gráficos, que serão apresentados neste estudo em números absolutos e percentuais.

Desta forma, esta pesquisa se apoiou em dois referenciais teóricos. O primeiro foi o referencial teórico de Bardin (Análise de Conteúdo), que deu subsídio para análise e foi capaz de proporcionar a compreensão e cruzamento de dados na manifestação do coletivo de forma simples e organizada dos ensinamentos e percepções encontradas no estudo. E para elaboração do protocolo (ainda em protótipo - slide), foram utilizados os dados coletados e analisados através de pesquisa bibliográfica em protocolos e trabalhos publicados na área, cujo mesmo será criado se a percepção dos docentes for positiva para seu uso futuro no ensino, utilizando como referência o trabalho sobre "Protocolo de cuidados à saúde e organização do serviço" de Marcos Werneck, onde se observa que

a elaboração de protocolos é um longo processo e sua efetiva implantação nem sempre ocorre de maneira imediata, sendo necessário que o protocolo passe por um período de construção participativa ${ }^{4}$.

Foram convidados a participar da pesquisa 40 docentes da graduação em enfermagem, do primeiro ao último semestre do curso, independente de ministrarem aula na área teórica ou prática, sendo que, destes, 18 docentes aceitaram participar da pesquisa e responderam o questionário dentro do prazo estipulado no cronograma de pesquisa.

Para análise das respostas, os docentes participantes da pesquisa foram nominados por Deuses da mitologia grega, preservando assim a sua identidade. Dessa forma, assim como os "Deuses", os docentes têm a atribuição de mediar e coordenar as vivências por quais os alunos passarão, demonstrando o pleno poder e consciência de seu papel ao auxiliar os passos no caminho dos novos profissionais.

\section{RESULTADOS E DISCUSSÃO}

Após período de preenchimento do questionário online pelos sujeitos, ocorreu a análise dos dados coletados através das respostas dos participantes. Dessa forma, buscou-se dividir a discussão em dois subtemas:

1. Caracterização dos Participantes

2. Viabilidade da Implantação do Protocolo de Ensino

\section{Caracterização dos Participantes}

Através da análise das respostas do questionário, verificou-se que os 18 (100\%) participantes são do sexo feminino, 4 (22\%) são formadas há mais de 10 anos e conforme pode ser conferido nos Gráficos 1 e 2, 14 (78\%) são formadas há mais de 20 anos. Além disso, 13 (72\%) são mestres e 5 (28\%) doutores, conforme ilustram os Gráficos 1 e 2 .

Quanto as áreas em que as participantes lecionam na graduação, dois (11\%), lecionam apenas na área de estágio, dois $(11 \%)$ na área teórica e laboratório, nove (50\%)

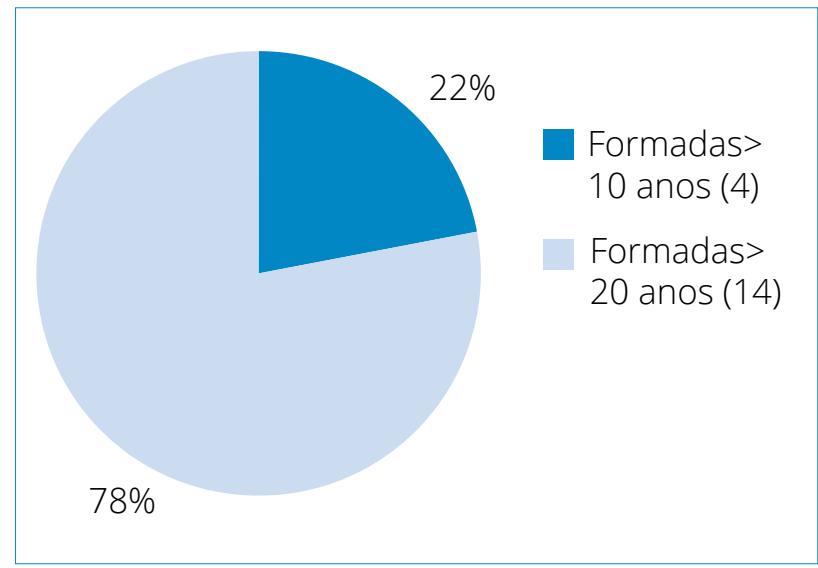

Gráfico 1. Tempo de Formação dos Docentes.

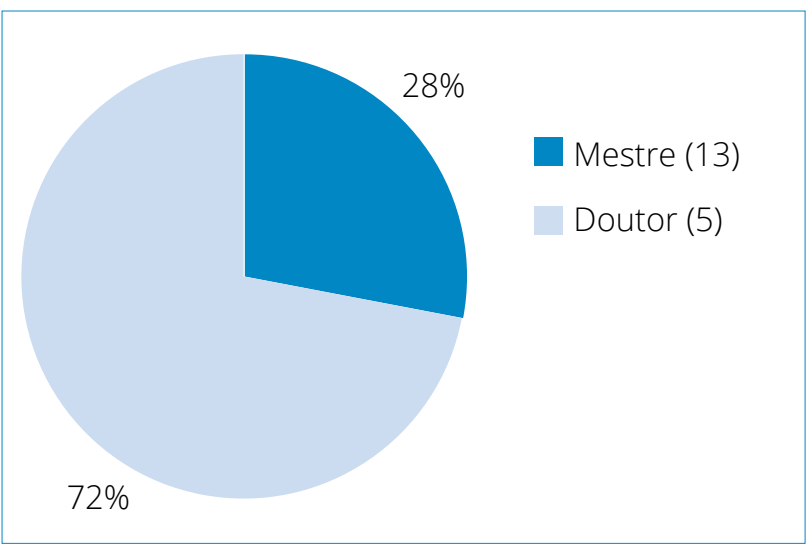

Gráfico 2. Titulação do Docente. 
na área de estágio e teórica, e cinco (28\%) lecionam nestas três áreas (estágio, teoria e laboratório), conforme demonstrado no Gráfico 3.

\section{Viabilidade da Implantação do Protocolo}

Foram realizadas sete perguntas relacionadas diretamente a opinião das docentes participantes frente a possibilidade de implantação do protocolo, conforme ilustra a Tabela 1.

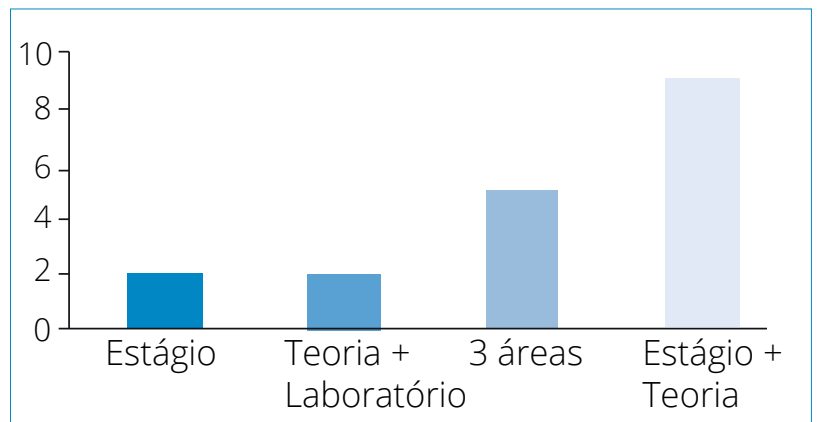

Gráfico 3. Área que atuam na graduação em Enfermagem
Dentro deste segundo subtema, foram analisadas as respostas das docentes ao questionário e categorizadas e tematizadas de acordo com o referencial teórico sobre análise de conteúdo de Bardin, que visa a categorização das respostas que mais aparecem e a tematização destas em diferentes itens para serem analisados e discutidos separadamente, buscando melhor descrição e definição das respostas encontradas no presente estudo.

A docente que descreveu que $\boldsymbol{n} \tilde{\boldsymbol{a}} \boldsymbol{0}$ acredita ser importante o ensino de estomaterapia na graduação de enfermagem, afirma:

Não. Acho a área de especialização e pode ser dada como curso de extensão. (Éros)

Debate-se que a prática profissional é essencial na formação do enfermeiro; porém, sem um conhecimento básico e norteador para seus cuidados, esta se torna apenas uma ação sem o elemento crítico-reflexivo essencial na sua atuação. Sendo assim, é preciso considerar a realidade e fundamentar-se nela como geradora dos processos de mudança e iluminadora dos caminhos a serem alterados e percorridos, para que

Tabela 1. Categorização das respostas às questões abertas.

\begin{tabular}{|c|c|c|}
\hline Pergunta & Resposta & Justificativa \\
\hline \multirow{2}{*}{ Experiência com estomaterapia? } & $\mathrm{SIM}-12(67 \%)$ & A experiência pessoal de cada docent \\
\hline & NÃO - $6(33 \%)$ & $\begin{array}{c}\text { que nem todas tiveram vivência com estoma em } \\
\text { sua vida profissional }\end{array}$ \\
\hline \multirow{2}{*}{$\begin{array}{l}\text { Importância do ensino de } \\
\text { estomaterapia na graduação de } \\
\text { enfermagem? }\end{array}$} & SIM - $17(94 \%)$ & $\begin{array}{c}\text { Aumento da Demanda; Melhora na assistência; } \\
\text { Preparo profissional }\end{array}$ \\
\hline & $\mathrm{NA} O-1(6 \%)$ & Area de especialização \\
\hline \multirow{3}{*}{$\begin{array}{l}\text { Ensino padronizado proporciona } \\
\text { um aprendizado mais adequado? }\end{array}$} & $\mathrm{SIM}-9(50 \%)$ & $\begin{array}{c}\text { Fixa/Norteia melhor o conhecimento/ } \\
\text { aprendizado }\end{array}$ \\
\hline & $N \tilde{A O}-1(6 \%)$ & $\begin{array}{c}\text { Apenas a vivência e não deve se restringir a um } \\
\text { semestre }\end{array}$ \\
\hline & DEPENDE - $8(44 \%)$ & Conteúdo adequado e atrativo \\
\hline \multirow{3}{*}{$\begin{array}{l}\text { Protocolo de ensino de } \\
\text { estomaterapia na graduação } \\
\text { favoreceria atuação docente? }\end{array}$} & $\operatorname{SIM}-11(61 \%)$ & Norteia e padroniza o ensino \\
\hline & $N A \tilde{A} O-3(17 \%)$ & Falta de experiência \\
\hline & DEPENDE - $4(22 \%)$ & Exigência do conteúdo na prática (estágio) \\
\hline \multirow{2}{*}{$\begin{array}{l}\text { Conteúdo padronizado de } \\
\text { estomaterapia favoreceria } \\
\text { aprendizado do aluno? }\end{array}$} & SIM - $10(56 \%)$ & $\begin{array}{l}\text { Auxilia e traz segurança para a prática } \\
\text { profissional/Campo de estágio) }\end{array}$ \\
\hline & DEPENDE - 8 (44\%) & $\begin{array}{l}\text { Inicia o ensino, porém precisa de iniciativa do } \\
\text { aluno (6) }\end{array}$ \\
\hline \multirow{2}{*}{$\begin{array}{l}\text { Ensino padronizado através de } \\
\text { objeto de aprendizagem permite } \\
\text { que o aluno tenha melhor } \\
\text { aprendizado e fixação do conteúdo? }\end{array}$} & SIM - $11(67 \%)$ & $\begin{array}{c}\text { Tecnologia auxilia e motiva na fixação do } \\
\text { aprendizado (6) }\end{array}$ \\
\hline & DEPENDE - 7 (39\%) & Interesse do aluno (3) \\
\hline $\begin{array}{l}\text { Utilizaria objeto de aprendizagem } \\
\text { sobre estomaterapia? }\end{array}$ & SIM $-14(78 \%)$ & A maioria dos docentes utilizariam o $\mathrm{OA}$ \\
\hline
\end{tabular}

OA: Objeto de Aprendizagem 
o enfermeiro seja capaz de tomar decisões sobre o cuidado de feridas, é necessário um conhecimento científico prévio ${ }^{8,9}$.

Aumento da demanda (6)

A maioria das participantes acredita ser importante o ensino de estomaterapia devido ao aumento da demanda de pacientes que se encontram em situações vulneráveis com presença de feridas e/ou estomias. Consta abaixo a fala de docentes para justificar sua importância:

Sim. Porque hoje há muitos pacientes nessa condição. (Adonis)

Como exemplo do crescente número de pacientes atendidos com feridas, como a úlcera por pressão (UPP), que a Organização Mundial da Saúde (OMS) utiliza a incidência e prevalência das UPP como indicadores para determinar a qualidade dos cuidados prestados. Além disso, a National Ulcer Advisory Panel (NPUAP) indica que a prevalência desta nos hospitais dos Estados Unidos da América (EUA) varia de 3 a 14\%, aumentando para 15 a 25\% nos casos de pacientes que se encontram em repouso absoluto. Por outro lado, no Brasil, estudos na literatura demonstram que a taxa de incidência em pacientes hospitalizados em UTI varia de 10,6 a 55,0\%, bem como sabe-se que até 95\% destes casos de UPP poderiam ser prevenidos ${ }^{10}$. Outra estatística descrita aponta que as ulcerações de pé atingem cerca de $15 \%$ dos pacientes com diabetes mellitus; e estas têm altos índices de recidiva ${ }^{11}$.

Além disso,é fundamental o conhecimento frente a incontinências, tendo como objetivo a prevenção de dermatites associadas a umidade ou fraldas, ou ainda a importância do controle destas para prevenção de infecções, sendo ambos aspectos gerenciados quando se fala em aumento do tempo de internação de pacientes.

Dessa forma, observa-se a importância de tal ensino, visto que os alunos se depararão se não em campo de estágio, em algum momento de sua vida profissional, com estes pacientes e, devido a isso, devem ser retentores dos conhecimentos necessários para o manejo de seus cuidados.

\section{Fixa/Norteia melhor o conhecimento (4)}

Observa-se que entre as nove docentes que afirmaram que o ensino padronizado proporciona aprendizado adequado, ressalta-se a categoria: fixa/ norteia o conhecimento/ aprendizado, conforme demonstra o relato a seguir:
Sim. Pois norteia e capacita o fazer terapêutico do aluno. (Éros)

O ensino padronizado traz para a prática clínica maior segurança para o aluno na hora de prestar assistência e futuramente em sua vida profissional, conduzindo-o a um movimento de conhecimento e atitudes que o tornem capaz para o trabalho.

Dessa forma, o cuidado de enfermagem pode ser definido como um fenômeno resultante do processo de cuidar, do desenvolvimento de atitudes, ações e comportamentos no sentido de promover, manter ou recuperar a dignidade e a totalidade humana. Essas ações devem ser fundamentadas no conhecimento científico, na experiência, na intuição, no pensamento crítico, ou seja, este cuidado também deve ser embasado em evidências científicas ${ }^{12}$.

\section{Conteúdo adequado e atrativo (3)}

Quanto as docentes que afirmaram que tal contestação depende, a principal justificativa é de que, para isso, o conteúdo a ser ensinado precisa ser adequado e atrativo, sendo esta questão transcrita na resposta abaixo:

A proposta precisa ser bem atrativa, bem estruturada [...]. (Afrodite)

Para que o conteúdo ensinado seja fixado, é preciso que este seja adequado no sentido de ampliar o conhecimento do aluno e incentivá-lo a buscar capacitação em suas ações como enfermeiro, firmando assim um compromisso, não só dos docentes, como também dos alunos frente ao tema abordado e ações a serem praticadas, não apenas como obrigação na grade curricular ao aluno, mas pelo reconhecimento da importância do tema na prática profissional de enfermagem.

\section{Vivência na prática profissional (1)}

Para a docente que declarou que este método não proporciona aprendizado adequado e que este conteúdo necessita da vivência profissional não devendo se restringir a um semestre, cabe trazer o debate frente à importância do preparo do aluno quanto ao embasamento científico como instrumento de apoio para esta vivência profissional. Pois, além de ter a meta de treino prático, o estágio é o processo pedagógico de formação profissional que tenta interligar, como uma ponte, a formação teórica e científica, 
possibilitando ao estudante estabelecer correlações entre o referencial teórico e as situações do cotidiano². Sendo assim, para que o aluno possa adquirir segurança em suas ações, é necessário que este tenha um conhecimento básico bem delineado, pois este serve como um norteador.

\section{Norteia e padroniza o ensino (5)}

Entre as 11 docentes que disseram que o protocolo favoreceria suas atuações como docentes, a principal justificativa é de que este norteia o ensino:

Sim. Porque um protocolo de ensino de ensino de estomaterapia seria como um norteador. (Zeus)

Evidencia-se um desafio para os docentes no que concerne a preparação dos alunos para carreira profissional, sendo esta uma grande preocupação relacionada ao ensino de seus alunos para prestarem uma assistência individualizada, sistematizada, avaliando e prescrevendo uma cobertura ideal para a cicatrização. Esta preocupação é o primeiro passo para contribuição do desenvolvimento dos alunos, visto que estes procuram os docentes como apoio para construírem um mecanismo de coping ${ }^{2,8,13}$.

Para isso, é necessário que os docentes tenham domínio das técnicas e estratégias para ensino, auxiliando os alunos em sua busca pela capacidade profissional, cabendo ressaltar que uma padronização de ensino através de um protocolo auxiliaria quanto ao conteúdo a ser ensinado, permitindo que este seja transmitido com segurança e efetividade, servindo como um norteador para o docente e criando um padrão que traga segurança de que o conteúdo foi repassado.

\section{Exigência do conteúdo na prática (estágio) (2)}

Para as docentes que disseram que tal questão depende, suas justificativas são que este protocolo auxiliaria se a matéria/estágio exigir tal conteúdo, porém não deve ser a única contribuição. Tal contestação é demonstrada a seguir:

Depende. Seria uma contribuição importante, porém não deve ser a única. (Deméter)

Para estes, o protocolo auxiliará de acordo com a exigência da prática assistencial e, sendo assim, esta não deve ser a única contribuição para o ensino do aluno, devendo permitir novas discussões e reestruturações.

Feridas crônicas são encontradas em todos os segmentos sociais. No Brasil, não é diferente. De forma generalista, pode-se citar como causa básica a grande demanda e busca de atendimento e a carência de recursos para atendê-la adequadamente ${ }^{14}$. Sendo assim, o protocolo pode trazer um enriquecimento e direcionamento do ensino, porém é necessário que o docente tenha bem definido a importância de seu papel e conhecimentos específicos e individuais para proporcionar o melhor aprendizado e apoio na formação dos alunos.

\section{Falta de experiência (3)}

Para as docentes que disseram que o texto não favoreceria suas atuações, a justificativa é de que esta é uma área muito específica e por elas não atuarem e/ou não terem experiência na área:

Não. Porque não atuo com esta especialidade de pacientes. (Apolo)

Surge aqui a contestação de que esta área de ensino contemplaria uma especialidade complexa ou a falta de experiência no cuidado, assuntos estes discutidos nos itens anteriores, onde ficou evidente o aumento no número de atendimentos a pacientes com feridas e estomias, e a necessidade do preparo do profissional enfermeiro que lidará diretamente com esta assistência. Ainda, por formação, o enfermeiro deve estar capacitado com um conhecimento teórico básico sobre o tema. Como exemplo, pode-se citar docentes da matéria de gestão, que na maioria das vezes não atuam diretamente na assistência, mas devem abordar os conceitos de cuidados com UPP devido ao reflexo desta incidência nos custos, tempo de internação e condições de trabalho de sua equipe.

\section{Auxilia e traz segurança para a prática}

profissional/Campo de estágio (7)

As justificativas das docentes que afirmaram que o conteúdo padronizado favoreceria o aprendizado do aluno foram exemplificadas abaixo:

Sim. Favorece porque irá padronizar as informações na abordagem do tema, o aluno terá o material didático, facilitando a aplicabilidade do ensino clínico (estágio).(Selene) 
É de se esperar que o emprego do protocolo possibilite melhor conhecimento do padrão cultural e de suas demandas, além da construção de um processo de trabalho no qual haja elaboração de metas que permitam avaliar processos e resultados, conduzindo a avaliações mais seguras e constantes que leve à incorporação de novas tecnologias ${ }^{4}$.

Além do conhecimento, o cuidar envolve o corpo físico e o espaço íntimo/subjetivo do indivíduo. Esse procedimento não pode ser realizado apenas como uma ação técnica, pois envolve uma relação, mesmo que temporária, entre dois seres humanos ${ }^{2}$. Dessa forma, pode-se dizer que o protocolo delinearia uma assistência efetiva, permitindo espaço para o desenvolvimento e trabalho frente a questões reflexivas, emocionais e éticas que envolvem tal cuidado.

\section{Inicia o ensino, porém precisa de iniciativa do aluno (6)}

Quanto as docentes que disseram que tal questão é relativa, sua principal justificativa é de que este apenas inicia o aprendizado do aluno e necessita de preparo/interesse do mesmo, como descreve a resposta:

Favorece se o aluno for ativo no aprendizado, que tenha que buscar informação. (Hades)

O emprego responsável de protocolos deve ser consequência de um processo de planejamento, pois gera a necessidade de que os profissionais estejam atentos e deflagrem um movimento de acompanhamento constante. A depender de como ocorrer o processo de discussão, adoção e implantação, é possível afirmar a efetividade destes como instrumentos de mudanças e de aumento da capacidade crítica dos profissionais e melhora do seu desempenho ${ }^{4}$.

Sendo assim, não basta apenas implantar um protocolo na instituição. É necessário que os profissionais e alunos estejam preparados para interagir com tal e que estejam envolvidos com o conhecimento de forma a levá-lo com qualidade para o campo de estágio, tendo consciência da importância de tal conhecimento no cuidado de feridas, bem como seu papel em busca de excelência.

\section{Tecnologia auxilia e motiva a fixação do aprendizado (6)}

A principal justificativa das docentes que responderam que a tecnologia auxilia e motiva a fixação do aprendizado foi de que a tecnologia e recursos interativos são importantes na fixação:
Sim. Porque hoje existem muitos recursos tecnológicos que contribuem positivamente no aprendizado do aluno, inclusive na sua fixação. (Deméter)

Para que o conteúdo ensinado seja assimilado corretamente é preciso que este seja adequado a proposta de ensino de estomaterapia da graduação de enfermagem e para melhor compreensão pelos alunos necessita ser interativo e atrativo para despertar seu interesse.

Sendo assim, de acordo com as respostas das docentes frente à utilização de $\mathrm{OA}$, observa-se que, quando este está integrado a um programa com ferramentas e instrumentos que permitam a interação, seu conteúdo transmite os conceitos corretos a serem ensinados e a sua projeção e arquitetura trazem uma formatação atrativa para o aluno, bem como sua utilização e feedback são positivos.

\section{Interesse do aluno (3)}

E ainda, para as docentes que responderam que depende, estas acreditam principalmente que o aprendizado depende do interesse do aluno, devendo este ser ativo em busca de seu conhecimento:

Depende. [...] O aluno precisa ter vontade de aprender... (Prometheus)

O conhecimento é concebido como resultado da ação do sujeito sobre a realidade, estando o aluno na posição de protagonista no processo de aprendizagem ${ }^{15}$. Sendo assim, conforme debatido em alguns tópicos anteriores, para que o ensino seja melhor compreendido pelo aluno é preciso que este adote uma postura proativa referente a sua busca por capacitação profissional.

Dessa forma, verifica-se que a maioria das docentes é a favor da aplicação de um protocolo de ensino de estomaterapia na graduação de enfermagem através de um objeto de aprendizagem, relatando que o utilizariam. Porém, para este ser efetivo há necessidade de ser muito bem elaborado, respondendo aos princípios propostos de ensino da graduação.

Certamente, este trabalho finalizado prosseguirá para a futura avaliação e validação junto ao corpo discente, o que acontecerá em outro momento de pesquisa tendo em vista o seu olhar enquanto usuário do OA. 


\section{CONCLUSÃO}

Observou-se que a maioria das docentes participantes da pesquisa acreditam que o ensino padronizado auxiliaria de alguma forma sua atuação docente e o aprendizado dos alunos. Porém, para que isso seja efetivo, deixam explícito a necessidade do envolvimento de alunos e docentes com o conteúdo a ser ministrado, sem a limitação do conhecimento apenas baseado no objeto de aprendizagem online, o que deverá ser desenvolvido também através da pesquisa e da prática clínica.
Cabe ressaltar que, na amostra de sujeitos investigados, não surgiu um docente que tivesse especialização em estomaterapia, o que demonstra ainda mais a necessidade de padronização e disponibilização de Objetos de Aprendizagem de qualidade, que possam auxiliar na atuação docente nesta área, mediante, inclusive, a validação prévia de especialistas ao material a ser criado. Concluiu-se que o cuidado adequado com feridas, estomias e incontinências é de extrema importância e o resultado aqui exposto revela a necessidade de se repensar o ensino para o preparo suficiente e adequado a alunos da graduação e futuros profissionais frente aos temas que envolvam a estomaterapia.

\section{REFERÊNCIAS}

1. Paula MAB. Aspectos da assistência domiciliar à pessoa com feridas. Rev Estima. 2011;9(2):39-44.

2. Salomé GM, Espósito VHC. Vivências de acadêmicos de enfermagem durante o cuidado prestado às pessoas com feridas. Rev Bras Enferm. 2008;61(6):822-7.

3. Farias DECS, Lorencette DAC. A função administrativa do enfermeiro na ótica dos estudantes de graduação. Cad Centro Universitário São Camilo. 2005;11(2):61-75.

4. Werneck MAF, Faria HP, Campos KFC. Protocolo de cuidados à saúde e organização do serviço. Belo Horizonte: Nescon/ UFMG; Disponível em: Https://www.nescon.medicina.ufmg. br/biblioteca/registro/Protocolo_de_cuidado_a_saude_e_de_ organizacao_de_servico_1/223

5. IEEE Learning Techology Standards Committee. Draft Standard for Learning Object Metadata. Learning Technology Standards Comittee Website. [internet] 2000. Disponível em http://ltsc.ieee.org/

6. Silveira AM, Santos LM, Trevisan MCB, Bisognin E, Fagan $\mathrm{SB}$, Bisognin V. Desenvolvimento de um Objeto de Aprendizagem sobre a poluição global. Rev Renote. 2006; 4(2): 1-8. Disponível em: http://www.seer.ufrgs.br/renote/ article/viewFile/14292/8208

7. Tarouco LMR, Fabre MCJM, Tamusiunas FR. Reusabilidade de objetos educacionais. Rev Renote. 2003;1(1). Disponível em: $\quad$ http://www.seer.ufrgs.br/index.php/renote/article/ view/13628/7697
8. Silva KL, Sena RR. A formação do enfermeiro: construindo a integralidade do cuidado. Rev Bras Enferm. 2006;59(4):488-91.

9. Caliri MHL, Martins GP. Análise da produção científica da enfermagem brasileira na área de feridas crônicas e meios utilizados para sua disseminação. Rev Estima. 2008;6(1):14-21.

10. Soares DAS,Vendramin FS, Pereira LMD, Proença PK, Marques MM. Análise da incidência de úlcera de pressão no Hospital Metropolitano de Urgência e Emergência em Ananindeua, PA. Rev Bras Cir Plást. 2011;26(4):578-81.

11. Rezende KF, Nunes MAP, Melo NH, Malerbi D, Chacra AR, Ferraz MB. Internações por pé diabético: comparação entre o custo direto estimado e o desembolso do SUS. Arq Bras Endocrinol Metabol. 2008;52(3):523-7.

12. Santos ROM, Vieiral GCA, Brandão ES, Cavalcanti ACD. Cuidados de enfermagem no tratamento de feridas: uma pesquisa bibliográfica. Rev Estima. 2008;6(4):9-12.

13. Morais GFC, Oliveira SHS, Soares MJGO. Avaliação de feridas pelos enfermeiros de instituições hospitalares da rede pública. Texto \& Contexto. 2008;17(1):98-105.

14. Cunha NA. Sistematização da assistência de enfermagem no tratamento de feridas crônicas [Projeto online]. Olinda; 2006. Disponível em: http://www.abenpe.com.br/diversos/sae_tfc.pdf

15. Behar PA, Passerino L, Bernardi M. Modelos pedagógicos para educação a distância: pressupostos teóricos para a construção de objetos de aprendizagem. Rev Renote. 2007;5(2). 